\title{
Формирование среды реализации цифровых инициатив сотрудников банка
}

\author{
Тарас Гриценко, Жанна Передера*, Анна Теряева \\ Дальневосточный федеральный университет, г. Владивосток, Россия
}

\author{
Информация о статье \\ Поступила в редакиию: \\ 02.11 .2018 \\ Принята \\ к опубликованию: \\ 21.05.2019 \\ УДК 331.108 .4 \\ JEL M15
}

\section{Ключевые слова:}

банковский сектор, цифровая экономика, международные рейтинги, кадры и образование, цифровые инициативы, самообучение, среда реализации цифровых инициатив, оценки Кирпартрика и МакГи

Keywords:

the banking sector, the digital economy, international ratings, personnel and education, digital initiatives, self-study, the environment of implementation of digital initiatives, Kirpatrick and McGee assessments

\begin{abstract}
Аннотация
В работе рассматривается возможность формирования в банковском секторе среды, в которой сотрудники смогут самостоятельно реализовывать иифровые инициативы для развития компании и самообучения. Обоснована необходимость её наличия. Проведен анализ соответствия поставленной проблемы российским и мировым трендам на основе изучения федеральных программ и оценок рейтинговых агентств. В результате исследования разработан бизнес-процесс реализации ичифровых инициатив, проведен конкурентный анализ его преимуществ и недостатков перед традиционным подходом к обучению.
\end{abstract}

Formation of the Implementation Environment for Digital Initiatives of Bank Employees

Taras Gritsenko, Zhanna Peredera, Anna Teryaeva

\begin{abstract}
The article discusses the possibility of forming in the banking business an environment in which employees will be able to independently implement digital initiatives for the development of the company and self-learning. The necessity of its presence is grounded. The analysis of compliance of the problem with the trends in Russia and the world based on the study of Federal programs and ratings agencies. To attract new staff with the necessary knowledge, banks have a number of tools - business classes, sponsorship programs, mentoring, hackathons, management fights, case-championships, etc. It has been revealed that new professionals with technical skills can solve complex problems and generate products. But it's difficult for them to dive into the banking sector, study its features and offer their own solutions to problems. It was also revealed that the company is interested in product results that are practice oriented. Combining product results and training is only possible by creating an environment in which they can discuss their ideas, find support and implement them. As a result, a business process for the implementation of digital initiatives has been formed, a competitive analysis of its advantages and disadvantages over the traditional approach to training has been conducted.
\end{abstract}

* Aвтор для связи peredera.zhs@students.dvfu.ru 
strategies. The leading method of research is the definitions according grouping to the principles of the matrix method. It was revealed that the economic security concept is disclosed using factors freely combined into three groups (includes: sustainability, protection of interests, ensuring sovereignty), and the most common definitions are built using words-markers: state, security, advantage, process. One of the main study results is an algorithm for constructing the definition of the economic security concept, which allows to model and refine the definition of the concept based on the initial categories, considering the economic context. The author's definition is also formulated, which reflects the interrelation of such components as the protection of interests, the impact of threats, the stability preservation, independence, ensuring development, self-adaptation and self-reproduction.

\section{Введение}

В 2017 г. Правительством Российской Федерации была разработана и утверждена программа по созданию условий для перехода страны к цифровой экономике. Актуализация вопроса была обусловлена 5-8-летним отставанием от ряда ведущих стран [1].

Цель исследования заключается в разработке процесса формирования среды реализации цифровых инициатив сотрудников, обеспечивающей повышение уровня цифровизации в банковском секторе.

Несмотря на то, что в банковском секторе существует множество методик обучения сотрудников, они не обеспечивают развитие цифровизации бизнес-процессов. В исследовании предложен новый подход к организации обучения банковских работников путем формирования среды реализации цифровых инициатив.

\section{Анализ уровня цифрового развития России}

Для общего понимания термина цифровой экономики в стратегии развития России принято следующее его определение: цифровая экономика - это хозяйственная деятельность, в которой ключевыми факторами производства являются данные в цифровом виде, обработка больших объемом и использование результатов анализа которых по сравнению с традиционными формами хозяйствования позволяют существенно повысить эффективность различных видов производства, технологий, оборудования, хранения, продажи, доставки товаров и услуг [2]. Оценку международной позиции России в цифровой экономике можно провести с помощью комплексного обзора рейтингов авторитетных изданий (см. табл.).

Таблийа

Позиция России в рейтингах международных организаций по развитию циирровой экономики

\begin{tabular}{|c|c|c|c|c|c|c|c|c|}
\hline № & Страна & Оценка & № & Страна & Оценка & № & Страна & Оценка \\
\hline \multicolumn{3}{|c|}{$\begin{array}{l}\text { IMD World Digital Competi- } \\
\text { tiveness Ranking (2018) }\end{array}$} & \multicolumn{3}{|c|}{ ICT Development Index (2017) } & \multicolumn{3}{|c|}{ Global Cybersecurity Index (2017) } \\
\hline 1 & США & 100,0 & 1 & Исландия & 89,8 & 1 & Сингапур & 92,5 \\
\hline 42 & Тайланд & 65,2 & 44 & Португалия & 71,3 & 9 & Канада & 81,8 \\
\hline 43 & Россия & 65,2 & 45 & Россия & 70,7 & 10 & Россия & 78,8 \\
\hline 44 & Италия & 64,9 & 46 & Словакия & 70,6 & 11 & Япония & 78,6 \\
\hline 58 & Венесуэла & 24,7 & 176 & Эритрея & 9,6 & 165 & $\begin{array}{c}\text { Экваториальная } \\
\text { Гвинея }\end{array}$ & 0,0 \\
\hline
\end{tabular}




\begin{tabular}{|c|c|c|c|c|c|c|c|c|}
\hline \multicolumn{3}{|c|}{ Global Innovation Index (2018) } & \multicolumn{3}{|c|}{$\begin{array}{c}\text { The Networked } \\
\text { Readiness Index (2016) }\end{array}$} & \multicolumn{3}{|c|}{$\begin{array}{c}\text { E-Government } \\
\text { Development Index (2018) }\end{array}$} \\
\hline $\mathbf{1}$ & Южная Корея & 89,2 & $\mathbf{1}$ & Сингапур & 60 & $\mathbf{1}$ & Дания & 91,5 \\
\hline $\mathbf{2 4}$ & Исландия & 67,1 & $\mathbf{4 0}$ & Кипр & 46 & $\mathbf{3 1}$ & Израиль & 79,9 \\
\hline $\mathbf{2 5}$ & Россия & $\mathbf{6 6 , 6}$ & $\mathbf{4 1}$ & Россия & $\mathbf{4 5}$ & $\mathbf{3 2}$ & Россия & $\mathbf{7 9 , 6}$ \\
\hline $\mathbf{2 6}$ & Малазия & 64,7 & $\mathbf{4 2}$ & Польша & 45 & $\mathbf{3 3}$ & Польша & 79,2 \\
\hline $\mathbf{5 0}$ & Марокко & 43,9 & $\mathbf{1 3 9}$ & Чад & 22 & $\mathbf{1 9 3}$ & Сомали & 5,6 \\
\hline
\end{tabular}

Источник: составлено авторами на основе данных [3-8]

Международные организации дифференцированно определяют позицию России в мировой цифровой экономике, но все сходятся в том, что она входит в группу развивающихся, для которых переход особо важен.

\section{Значимость обогащения кадров цифровыми навыками}

Для оценки успешности предпринимаемых решений в рамках национальной стратегии развития страны выделено 5 направлений, по каждому из которых сформирован ряд KРI для оценки следования программе. Первое приоритетное направление - кадры и образование, целевыми показателями которого являются:

- 120000 выпускников образовательных организаций высшего образования по направлениям подготовки, связанными с информационнотелекоммуникационными технологиями;

- 800000 выпускников высшего и среднего профессионального образования, обладающих компетенциями в области информационных технологий на среднемировом уровне;

- 40\% населения, обладающего цифровыми навыками [2].

В 2018 г. двигателями российской цифровой экономики являются банки и отдельные сырьевые лидеры. Банковский сектор переживает трансформацию, обусловленную сменой поколений, отвечая на вызовы общества - отказ от операций с наличными средствами и зависимость от интернет-сервисов. Эти изменения вызывают потребность в технических навыках сотрудников и их готовности их нести позитивные изменения. Для преобразования кадровой составляющей банков в рамках политики цифровизации имеется два основных пути: 1) привлечение новых и 2) обучение существующих сотрудников.

Для привлечения новых кадров с необходимыми знаниями у банков есть ряд инструментов - бизнес-классы, спонсорские программы, менторство, хакатоны, управленческие поединки, кейс-чемпионаты и пр. Новые специалисты, обладающие техническими навыками, способны решать сложные задачи и генерировать продукты, но им сложно погружаться в банковскую сферу, изучать ее особенности и предлагать собственные решения проблем. Они чаще всего работают по техническому заданию, которое в зависимости от сложности и масштабности задачи постоянно корректируется. В этой ситуации, актуальным становится возможность инициаторам самостоятельно реализовывать свои идеи, для этого необходимо заниматься обучением кадров.

В банковском секторе также развиты практики по обучению сотрудников - презентации с тестами, удаленное обучение, образовательные сервисы, бизнес-тренинги и др. инструменты. Но работники, как правило, замотивированы в таком обучении лишь требованиями компании, что накладывает свои особен- 
ности в прохождении курса - недобросовестное отношение, закрытие задач в рамках жестких дедлайнов, объединение в коллективы для группового закрытия индивидуальных курсов и др. Также обязательное массовое обучение в основном является ознакомительным и связано прежде всего с изменениями в законодательстве и новыми продуктами банка, а для приобретения технических навыков необходимо самостоятельное изучение материала, необходимого при решении определенной задачи.

Кроме того, для компании интерес представляют продуктовые результаты, которые являются практико-ориентированными. Совместить продуктовые результаты и обучение кадров возможно лишь с помощью создания среды, в которой они смогут обсуждать свои идеи, находить поддержку и реализовывать их.

\section{Формирование среды реализации цифровых инициатив}

Для формирования среды в компании необходимо ввести роль - координатор цифровых инициатив. Эту роль можно прикрепить за отдельной штатной единицей или делегировать её функционал на действующего сотрудника. Координатор цифровых инициатив должен участвовать в согласовании запуска реализации идей, формировании индивидуальных подборок учебных материалов, организации встреч, составлении запросов в информационнотехнологическое (далее - ИТ) подразделение (см. рис.).

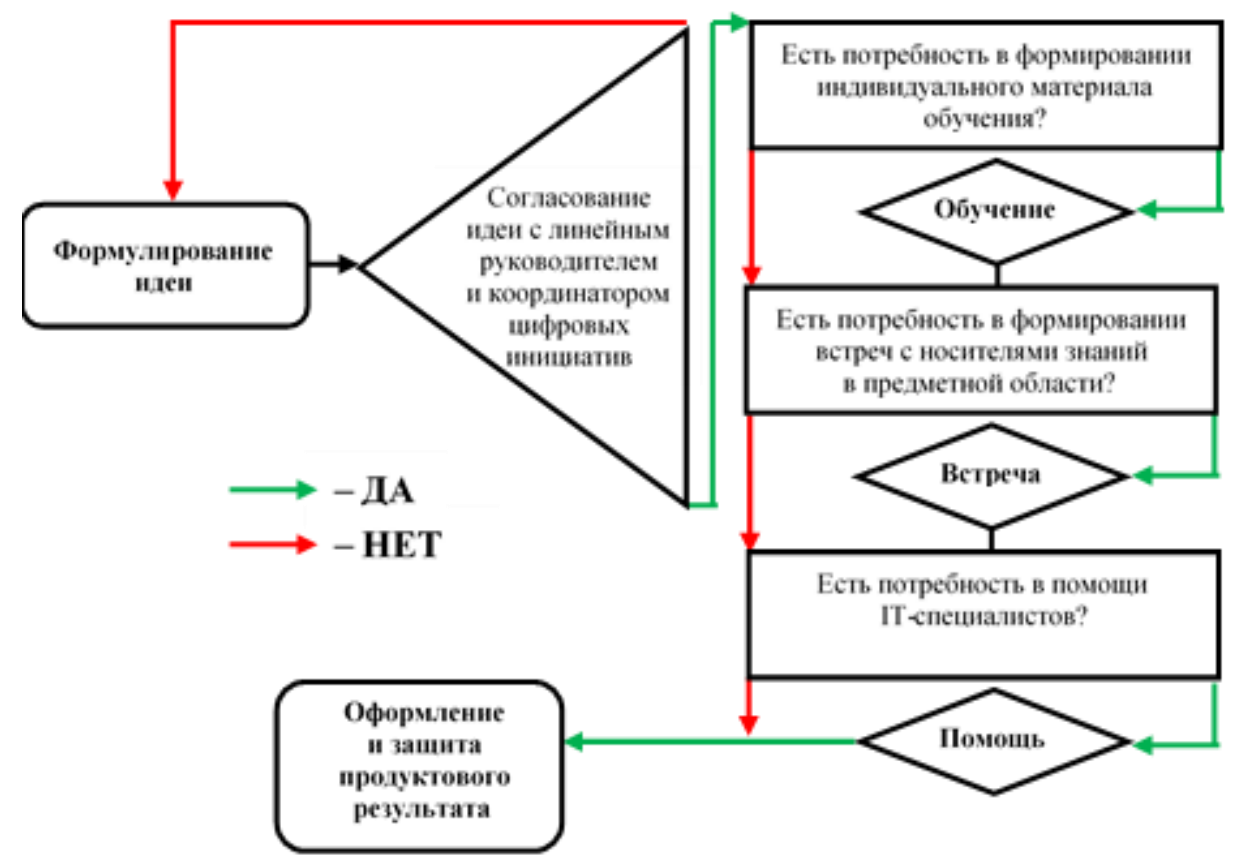

Рис. Процесс формирования среды реализации Источник: составлено авторами цифровых инициатив сотрудников банка

На первом этапе инициатору необходимо сформулировать свою идею, изложить ее в бумажном или электронном формате и подготовить к защите. Идея сначала согласовывается с линейным руководителем и координатором 
цифровых инициатив, например, в системе документооборота, а в последующем защищается на очном заседании. Если инициатива получает одобрение, то она вносится в реестр проектов, что является подтверждением того, что координатор должен оказывать помощь в реализации проекта по следующим направлениям:

- формирование индивидуального материала для обучения;

- организация встреч между инициатором и носителями знаний;

- помощь ИТ-специалистов, например, заявка на создание блоков кода или библиотек по техническому заданию.

В некоторых компаниях существуют практики, когда сотрудники вовлекаются в пересмотр бизнес-процессов, проектную деятельность, но эти активности, как правило, крупномасштабны. Авторская среда позволит решать еще и микропроблемы компании, возможно, даже на уровне отдельного сотрудника.

Рассмотрим кейс. Сотрудник выступил с инициативой разгрузить работу направления по формированию еженедельного отчета, который собирается путем объединения нескольких унифицированных файлов в единый свод. Он защитил активность и вышел к координатору цифровых инициатив с просьбой оказать помощь в формировании алгоритма запроса в отдельные файлы. Для этого координатор подобрал тематический материал по языку, который используется в компании. Сотрудник изучил его, но возникла сложность с тем, что алгоритмизированный запрос на открытие папки блокируется системой безопасности. На этом этапе инициатор идеи формирует запрос в ИТ для разъяснения причин и по потребности написания библиотеки, которая позволяла бы осуществлять запрос. В итоге, ИТ-специалисты дали пояснения, что блокировка обусловлена исторической ошибкой в коде безопасности и сформировали сложный обходной блок кода, который сотрудник смог самостоятельно разместить в своем алгоритме и запустить автоматическое формирование свода. В последующем этот же работник смог оказать помощь в поддержке схожей инициативы в соседнем направлении. Таким образом, компании удалось оптимизировать процесс, снизить трудозатраты на формирование отчетов, обучить сотрудника на уровне практико-применимых навыков, которыми он смог поделиться с коллегами в режиме «равный - равному».

\section{Обсуждение результатов}

Формирование среды реализации цифровых инициатив сотрудников банка характеризуется ключевым преимуществом перед другими методиками обучения - возможность компании оценить его эффективность. Как правило, для такой оценки используют классическую модель Д. Киркпартрика, включающую в себя четыре этапа:

- реакция (получение информации на уровне «нравится/не нравится» путем проведения анкетирования, оставления отзывов и другое);

- обучение (непосредственно сам процесс обучения и проверка путем проведения тестирования, опроса, разбора кейсов/заданий);

- поведение (определение того, как изменился подход сотрудников к работе, происходит ли применение полученных знаний и навыков);

- результат (как обучение повлияло на финансовые результаты деятельности сотрудников, каков продуктовый результат обучения) [2].

При традиционном обучении реализуемыми являются только два этапа описанной выше модели. Это не дает полного представления о результативно- 
сти мероприятия. При формировании среды реализации цифровых инициатив сотрудников банка можно будет оценить эффективность обучения по всем этапам модели Д. Кирпартрика, так как в конце разработанного процесса обучения сотрудник получает и представляет продуктовый результат, который является измеримым по всем применяемым методикам оценки, включая анализ ROI и бипараметрическую оценку МакГи. Первая позволит оценить финансовую результативность формирования такой среды, вторая - изменение бизнеспроцесса до и после обучения.

Таким образом, внедрение предложенного авторами процесса формирования среды реализации цифровых инициатив сотрудников банка позволит повысить уровень цифровизации в банковском секторе и получить краткосрочные измеримые продуктовые результаты.

\section{Список источников / References}

1. Вишневская А., Ларкина О., Денисова Е. Обучение персонала в финансовых организациях. [Vishnevskaya, O Larkina., Denisova E. Obuchenie personala v finansovyh organizaciyah [Training of personnel in financial organizations]. Available at: https://www.cfin.ru/management/people/dev_val/financial_institution.shtml

2. Об утверждении программы «Цифровая экономика Российской Федерации». Распоряжение Правительства РФ от 28 июля 2017 года №1632-р. [Ob utverzhdenii programmy «Cifrovaya ehkonomika Rossijskoj Federacii». Rasporyazhenie Pravitel'stva RF ot 28 iyulya 2017 goda №1632-r [On approval of the program «Digital economy of the Russian Federation». Order of the Government of the Russian Federation of July 28, 2017 №1632-p.].

3. Available at: http://government.ru/docs/28653.

4. IMD World Competitiveness Center. Available at: https://www.imd.org/wcc/worldcompetitiveness-center.

5. ICT Development Index. Available at: http://www.itu.int/net4/ITU-D/idi/2017/index.html.

6. Global Cybersecurity Index. Available at: https://www.itu.int/dms_pub/itu-d/opb/str/DSTR-GCI.01-2017-PDF-E.pdf.

7. World Economic Forum. Available at: http://reports.weforum.org.

8. United Nations E-Government Survey 2018. Available at: https://publicadministration.un.org.

9. Gloval Innovation Index 2018.2 Available at: https://www.wipo.int/edocs/pubdocs/en/wipo_pub_gii_2018.pdf.

\section{Сведения об авторе /About author}

Гриценко Тарас Степанович, магистрант, Школа экономики и менеджмента, Дальневосточный федеральный университет. 690022 Россия, г. Владивосток, о-в Русский, кампус ДВФУ, корпус G. E-mail: gritcenko_ts@students.dvfu.ru

Taras S. Gritsenko, Master Student, School of Economics and Management, Far Eastern Federal University. Building G, FEFU campus, Russky Island, Vladivostok, Russia 690922. E-mail: gritcenko_ts@students.dvfu.ru

Передера Жанна Сергеевна, магистрант, Школа экономики и менеджмента, Дальневосточный федеральный университет. 690022 Россия, г. Владивосток, о-в Русский, кампус ДВФУ, корпус G. E-mail: peredera.zhs@students.dvfu.ru

Zhanna S. Peredera, Master Student, School of Economics and Management, Far Eastern Federal University. Building G, FEFU campus, Russky Island, Vladivostok, Russia 690922. E-mail:peredera.zhs@students.dvfu.ru 
Теряева Анна Сергеевна, старший преподаватель базовой кафедры современного банковского дела, Школа экономики и менеджмента, Дальневосточный федеральный университет. 690022 Россия, г. Владивосток, о-в Русский, кампус ДВФУ, корпус G. E-mail: teryaeva.as@dvfu.ru Anna S. Teryaeva, Senior Lector of the Basic Department of Modern Banking, School of Economics and Management, Far Eastern Federal University. Building G, FEFU campus, Russky Island, Vladivostok, Russia690922.E-mail: teryaeva.as@dvfu.ru 